\title{
MSc student voices about learning together in an online academic conversation club: a collaborative student project
}

\author{
Anita Fromm \\ University of Hertfordshire, UK \\ Bolatito Adigun-Lawal \\ University of Hertfordshire, UK \\ Stella Akinmoju \\ University of Hertfordshire, UK \\ Nnenna Onyenucheya \\ University of Hertfordshire, UK \\ Frederick Otchere \\ University of Hertfordshire, UK \\ Victoria Udeh \\ University of Hertfordshire, UK
}

Keywords: Active Listening; Oral Paraphrasing; online synchronous communication; Covid-19.

\section{The challenge}

Conversations, to interact with others and exchange ideas, are important in higher education. The sudden shift to online learning caused by the Covid-19 pandemic has reduced opportunities for face-to-face conversations at universities in Britain (Dost et al., 2020) and has led to students experiencing stress and isolation (Carolan, et al., 2020). It has been a difficult learning experience for many first-year students.

Even in classrooms, many students do not participate as much as might be expected (Fromm, 2018). This may be because of shyness, which can be viewed positively or negatively (Ollin, 2008; Akinbode, 2015). In online learning, Grondin et al. (2019) maintain that communication difficulties are exacerbated because of poor connectivity and less noticeable non-verbal language. 


\section{The response}

To mitigate some of the difficulties mentioned above for groups of students, the tutor (first author) volunteered to facilitate online academic speaking clubs for groups of international students at a university in England. The aim of the clubs was to create speaking opportunities outside course content sessions to boost confidence in speaking, discuss ideas, improve participation, and make friends. To this end, the tutor decided to focus the teaching on Active Listening (AL) and Oral Paraphrasing (OP).

AL can enhance group relations and empathy (Gordon, 1951; Bodie et al., 2013; 2015; 2016). OP is a common conversation technique (Machi, 2018) and can help to clarify understanding in the workplace (Whitcomb and Whitcomb, 2013). AL and OP can be effective together in counselling conversations (Kuhn et al., 2018).

Teaching in the clubs focused on developing these skills in an academic and friendly online synchronous environment using Zoom ${ }^{\mathrm{TM}}$. The students in one of the club groups contributed to this research themselves; in that this was a participatory action research project that was arranged in two cycles. The first cycle explains and practises AL and OP in six one-hour meetings. These skills are related to lectures and texts that the students choose to discuss during the sessions. After one of the breakout rooms, a student explained: 'We took turns to paraphrase the paragraph orally using synonyms and our own words to then discuss and analyse it'.

The second cycle of four two-hour meetings revises AL and OP and culminates in the students participating in a student-led small-scale qualitative research project about their learning of $\mathrm{AL}$ and $\mathrm{OP}$. As students volunteered to attend the club outside lecture time, no preparation for the sessions or research project was set so the whole project took place during club meetings. This article focuses on the one club group, where both cycles have been completed. Ethics approval and programme lead permission were granted for the tutor, with an approved amendment to include the five participants who had consented to involvement. 


\section{Participants}

The five first-year MSc pre-registration Nursing participants were aged between 26 and 36; four female and one male; four Nigerian and one Ghanaian. English has been the principal language used throughout their education. They all arrived in England during lockdown in autumn 2020. Here it should be emphasised that none had met another tutor or student at the university in person until their first hospital practice placement in April 2021. The tutor inspired, guided, and taught the students (participants).

\section{The students' project}

In breakout rooms, participants worked out the research question: to what extent, if any, do MSc Nursing students at a university in England actively listen and orally paraphrase in synchronous online classes during Covid-19 restrictions?

This was conducted in May 2021 using a questionnaire consisting of open questions, written and circulated within the group only.

Thinking about qualitative methodology and analysis took place in breakout rooms in the last two meetings with minimum guidance. The students wrote the findings and discussion collaboratively in breakout rooms at the end of the final meeting, which took about two hours with a couple of short intervals for tutor support and tips.

\section{Findings and discussion (in participants' own words)}

Many issues arise with online learning that do not occur with in-person lectures. Many respondents reported issues with connectivity and a lack of face-to-face contacts.

Distractions such as performing domestic tasks, interruptions from other online participants, and distractions from children at home, among others, made it difficult for some to concentrate.

Several tactics were used by some respondents to reduce distractions. One person noted wearing headphones, another said they had to turn off notifications, and still another respondent kept their camera on all the time to keep awake. 
Oral Paraphrasing is another approach that students can use to get the most out of lectures, whether they are in person or online. Students were able to understand and comprehend lecture subjects covered in online lectures, analyse various research papers, and avoid plagiarism when writing academic essays by using Oral Paraphrasing.

In conclusion, Oral Paraphrasing is beneficial to listening more actively; it enhances communication between students when in breakout rooms, and subsequently also helps writing skills.

\section{Students' recommendations (in participants' own words)}

We would recommend using Active Listening and Oral Paraphrasing in online synchronous learning.

\section{Recommendations}

The students' recommendations are interesting because it confirms the tutor's idea that $A L$ and OP enhance communication and, most probably, participation. The tutor had not anticipated that OP would help with subsequent writing skills. For the tutor, organising meeting times and preparation was challenging in terms of time.

The students' findings suggest that Active Listening and Oral Paraphrasing can create speaking and learning opportunities in a supportive environment online. AL and OP appear to enhance online communication between group members in breakout rooms. The breakout rooms enabled the students to have conversations together without the tutor listening in, but the tutor could be consulted when required. It should be noted that the students were learning to communicate in an online environment and were learning how to research for their Masters for the first time. Some points in their findings relate to other online difficulties asked in the questionnaire.

In conclusion, AL and OP can be beneficial techniques to use in online communication but their use in higher education requires further research. 


\section{References}

Akinbode, A. (2015) 'The quiet learner and the quiet teacher', LINK, 1(2). Available at: https://www.herts.ac.uk/link/volume-1,-issue-2/the-quiet-learner-and-the-quietteacher (Accessed: 1 June 2021).

Bodie, G. D., Vickery, A. J. and Gearhart, C. C. (2013) 'The nature of supportive listening, I: exploring the relation between supportive listeners and supportive people', International Journal of Listening, 27(1), pp.39-49. https://doi.org/10.1080/10904018.2013.732408.

Bodie, G. D., Vickery, A. J., Cannava, K. and Jones, S. M. (2015) 'The role of "Active Listening" in informal helping conversations: impact on perceptions of listener helpfulness, sensitivity, and supportiveness and discloser emotional improvement', Western Journal of Communication, 79(2), pp.151-173. https://doi.org/10.1080/10570314.2014.943429.

Bodie, G. D., Cannava, K. E. and Vickery, A. J. (2016) 'Supportive communication and the adequate paraphrase', Communication Research Reports, 33(2), pp.166-172. https://doi.org/10.1080/08824096.2016.1154839.

Carolan, C., Davies, C. L., Crookes, P., McGhee, S. and Roxburgh, M. (2020) 'COVID 19: disruptive impacts and transformative opportunities in undergraduate nurse education', Nurse Education in Practice, 46, pp.102807-102807. https://doi.org/10.1016/j.nepr.2020.102807.

Dost, S., Hossain, A., Shehab, M., Abdelwahed, A. and Al-Nusair, L. (2020) 'Perceptions of medical students towards online teaching during the COVID-19 pandemic: a national cross-sectional survey of 2721 UK medical students', BMJ open, 10(1), pp. e042378-e042378. https://doi.org/10.1136/bmjopen-2020-042378.

Fromm, A. (2018) 'Speaking the target language outside the classroom in friendship groups: a comparative study of international and local modern language foreign 
students with a focus on employability', LINK, 3(2). Available at:

https://www.herts.ac.uk/link/volume-3,-issue-2/speaking-the-target-languageoutside-the-classroom-in-friendship-groups-a-comparative-study-of-internationaland-local-modern-foreign-language-students-with-a-focus-on-employability (Accessed: 1 June 2021).

Gordon, T. (1951) 'Group centered leadership and administration', pp. 320-383, in Rogers, C. (ed.) Client-centered therapy: its current practice, implications and theory. London: Constable.

Grondin, F., Lomanowska, A. M. and Jackson, P. L. (2019) 'Empathy in computermediated interactions: a conceptual framework for research and clinical practice', Clinical Psychology: Science and Practice, 26(4). https://doi.org/10.1111/cpsp.12298.

Kuhn, R., Bradbury, T. N., Nussbeck, F. W. and Bodenmann, G. (2018) 'The power of listening: lending an ear to the partner during dyadic coping conversations', Journal of Family Psychology, 32(6), pp.762-772. https://doi.org/10.1037/fam0000421.

Machi, S. (2018) 'Paraphrasing the "other": connecting participants in Japanese conversation', Journal. Faculty of Humanities, 67, pp.39-53. Available at: https://jwujp.academia.edu/SaekoMachi/Papers (Accessed 1 June 2021).

Ollin, R. (2008) 'Silent pedagogy and rethinking classroom practice: structuring teaching through silence rather than talk', Cambridge Journal of Education, 38(2), pp.265280. https://doi.org/10.1080/03057640802063528.

Whitcomb, C., and Whitcomb, L. (2013) Effective interpersonal and team communication skills for engineers. Hoboken: Wiley. https://doi.org/10.1002/9781118514283.

\section{Author details}

Anita Fromm is Widening Participation Champion in the School of Health and Social Work and Visiting Lecturer in Academic Skills in the Centre of Academic English at the 
University of Hertfordshire. Here she is working towards her Doctorate in Education.

Bolatito Adigun-Lawal, Stella Akinmoju, Nnenna Onyenucheya, Frederick Otchere, and Victoria Udeh are MSc students in fields of nursing. 